\title{
TOPOGRAPHIC AND STRUCTURAL ENAMEL CHANGES AFTER ORTHODONTIC PRIMER ABSENCE
}

\author{
Atia Abd Elwareth Abd Elrazik Yousif* and Amel M. Ezzat Abd Elhamid**
}

\begin{abstract}
The Aim: evaluation of changes of enamel topographic, structural and enamel minerals mass percentage (calcium and phosphorus) due to absence of orthodontic primer.

Materials and Methods: 20 orthodontic patients were enrolled in this study. All patients as a part of orthodontic treatment planned to extract first premolars. After ethical approval was granted by Research Ethics Committee of faculty of dentistry, Tanta University and written consent from each patient to participate in this study was obtained. The patients divided randomly into, Group (I): 10 patient's first premolar brackets bonded with light cured orthodontic composite without primer. Group (II): 10 patient's first premolar brackets bonded with light cured orthodontic composite with primer. Control group: for both groups bonding only first premolar in one side leaving the opposite side unbounded as a control. After 3 months according to the treatment plane the first premolar tooth extracted, brackets carefully removed, teeth sectioned buccolingually, enamel surface topography was scanned with scanning electron microscopy, calcium and phosphorus mass \% was measured using scanning electron microscopy - energy dispersive X ray analytical system (SEMEDX). The obtained data were histologically and statistically analyzed.
\end{abstract}

Results: despite the non-significant statistical difference between group (I) and group (II), or between either groups and control group more enamel defects and lower average calcium and phosphorus mass \% in group (I) than in group (II) due to absence of orthodontic primer in the form of enamel erosion, cracks and gaps between enamel rods and enamel surface.

Conclusions: orthodontic bonding using composite without primer can resulted in more enamel defects and non-significant decrease in the mean calcium and phosphorous mass percentage.

KEY WORDS: Enamel structure, Primer, SEM-EDX, calcium and phosphorus mass.

\footnotetext{
* Associate prof. Department of Orthodontic, Faculty of Dentistry, Tanta University Egypt.

** Associate prof. Department of Oral Biology, Faculty of Dentistry, Tanta University, Egypt
} 


\section{INTRODUCTION}

A three-step conventional procedure of orthodontic brackets bonding: etching, priming and bonding ${ }^{(1)}$ can provide adequate bonding between enamel and brackets is important in orthodontic, but a methods that avoid damage to the enamel during bonding are required. ${ }^{(2,3)}$ Self-etching primers for enamel conditioning sometimes used to avoid the de-calcification resulted from etching solution (phosphoric acid). ${ }^{(4)}$

Recently due to greater demand on chair time and cost reduction bonding of orthodontic brackets without primer has become an interesting topic as increasing the time and steps of bonding can increase the risk of moisture contamination. Primers are widely used for bonding orthodontic brackets. Primer mainly functions to improve the effectiveness of the final bond, claimed to protect the enamel from demineralization and reduce marginal leakage. However, many studies have been published investigating bonding with and without the use of an intermediate liquid resin.

Two-step orthodontic adhesives, without prior application of adhesive resin, has appeared on the market in order to decrease the time of bracket bonding procedure, ${ }^{(5)}$ which may decreases enamel wetness, decreasing the amount of adhesive left on the tooth after bracket removal. ${ }^{(6)}$

Numerous in vitro studies have shown that orthodontic adhesives without priming reached bond strength comparable to that found with primer application however; several studies have reported that; to achieve mechanical adhesion to enamel use of primer is required. ${ }^{(7,8)}$

Several vitro studies ${ }^{(9-14)}$ have stated that satisfactory bonding can be achieved without using orthodontic primer. Bazargani et al. (1991) $)^{(15)}$ Compared the failure rate with and without the use of primer and found a significant difference between both groups thus concluded that a higher failure rate in the no primer group (27\%) compared to the group with primer (4\%). This was statistically significant and claimed clinically significant by the authors

Tang et al. (2000) ${ }^{(16)}$ studied a chemically cured composite with and without primer and compared the bonding failure rate in both groups the brackets failure rates with and without the use of primer and concluded that both groups were nearly similar (5.62\% without primer and $6.22 \%$ with primer) and the rates of bracket failure were not affected by use of primer or not.

Banks and Richmond (1994) ${ }^{(17)}$ analyzed the risk of enamel decalcification with or without use of sealants and concluded a similar results. (Bracket failure rate was found to be similar in both groups) (4\% when primer is used and 3\% without primer).

Several studies had tested the bond strength of orthodontic brackets without the use of primer, so we wish to evaluate the effect of absence of orthodontic primer on enamel topographic structure and minerals mass percentage after three months in oral cavity.

\section{MATERIALS AND METHODS}

- This study was carried out in vivo over a period of six months

- It was statistically calculated in order to make study with power $80 \%$ it is obligated to finish 10 cases per each group

- Continued inclusion of patients in the study to overcome attrition bias due to loss patient cooperation, oral hygiene control or fractured brackets till desired number of cases (20 patients) got finished. All patients enrolled in this study were planned to extract first premolars as a part of orthodontic treatment plan after getting Ethical approval and written consent from each patient to participate in this study (According 
to the roles of ethical committee, Faculty of Dentistry, Tanta university). To avoid possible confounders, e.g. age, gender, all patients enrolled in this study were females with narrow age range (15-17 year).

Sample population: from out patients attending Orthodontic department, Faculty of dentistry, Tanta university.

\section{Selection criteria:}

The patients should fulfill the following criteria:

- Intact enamel surface buccally, without areas of cracks or hypo-plastic spots.

- Absence of any restoration.

- No previous chemical treatments; like bleaching or hydrogen peroxide or alcohol.

- Absence of any craniofacial anomalies or congenital enamel defects.

\section{Study sample was divided into three groups:}

Group (I): (10 patients) the first premolar brackets bonded with light cured orthodontic composite without primer (Orthomite LC)*. Figure (1)A
Group (II): (10 patients) the first premolar brackets bonded with light cured orthodontic composite with primer (Transbond XT)**. Figure (1)B

Control group: for both groups bonding only first premolar in one side leaving the opposite side unbounded as control.

Each patient was randomly allocated to either Group (I) or Group (II).

\section{Bonding procedure:}

1- Polishing teeth with: pumice and rubber cups with oil free water spray steam.

2- Isolation with: cotton rolls, cheek retractors and saliva ejector

3- Etching with: 37 phosphoric acid for 30 second the same acid etch was used for both groups and the acid etch supplied with the Orthomite material not used

4- Rinsing with: water for 30 second

5- Drying with: oil free air steam for 30 second

6- For group (1): a small amount of the Orthomite past which supplied without primer gently

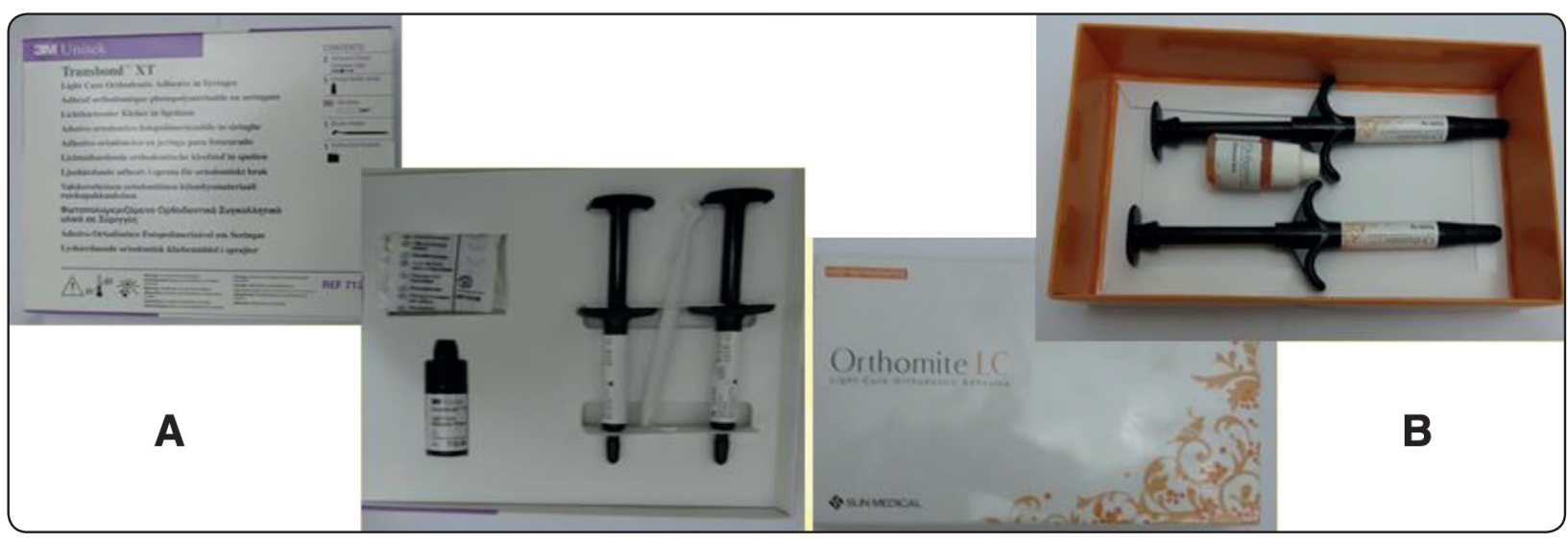

Fig. (1): A, Orthomite ; orthodontic composite without primer. B, Transbond XT ; orthodontic composite with primer.

*(SUN MEDICAL CO,LTD 571-2 Furutaka-cho,Moriyama,Shiga, 542-0044, Japan).

**(3M Unitek product, Monovia, Clifornia, USA). 
pressed on the base of the bracket and the bracket pressed against the tooth surface.

7- For group (II): A thin coat of the primer was applied then a small amount of the Transbond XT past gently pressed on the base of the bracket and the bracket pressed against the tooth surface.

8- Curing and Polymerization using a LED light; 30 seconds mesially and 30 Seconds distally.

9- The patient instructed to maintain good oral hygiene without using any mouth wash over the period of study

10- Recall every two weeks for oral hygiene instructions.

Control Group : for all patients the opposite side premolar left without bonding a bracket only polished with pumice at the start of the study.

Considering the attrition bias due to fractured brackets or patients drop out, inclusion of patients in the study continued till 20 patients completed three months with regular recall attendance visits.

After 90 days, the brackets were de-bonded, teeth were carefully extracted, scrapped and cleaned of remnants of soft tissues, disinfected and stored in distilled water before use. The teeth were sectioned from the roots with a low speed double sided diamond disk and continuous water spray irrigation. Then each crown was cut on a bucco-lingual line from lingual to half way the buccal surface then the two parts were separated using osteotome and hammer to have clean cuts and the cut surfaces were stored in distilled water. All specimens were examined by scanning electron microscope (JEOL JSM-6510LA Japan). The cut surfaces of the teeth were examined carefully occlusal and gingival to the bracket, Enamel structure, calcium and

phosphorus mass percentage was measured using scanning electron microscopy-energy dispersive $X$ ray analytical system (SEM-EDX) Figure (2), in Institute of Nuclear Energy, 10th District, Nasr City, Egypt. The obtained data were histologically and statistically analyzed..

\section{Statistical analysis}

Mean, standard deviation, and average values were calculated for each groups. Comparisons of the calcium and phosphorus mass percentage between the two groups were performed with student t-test. Significant differences for all statistical tests were predetermined at $\mathrm{P} \leq 0.05$. All statistical evaluations were made with a software program (SPSS version 15).

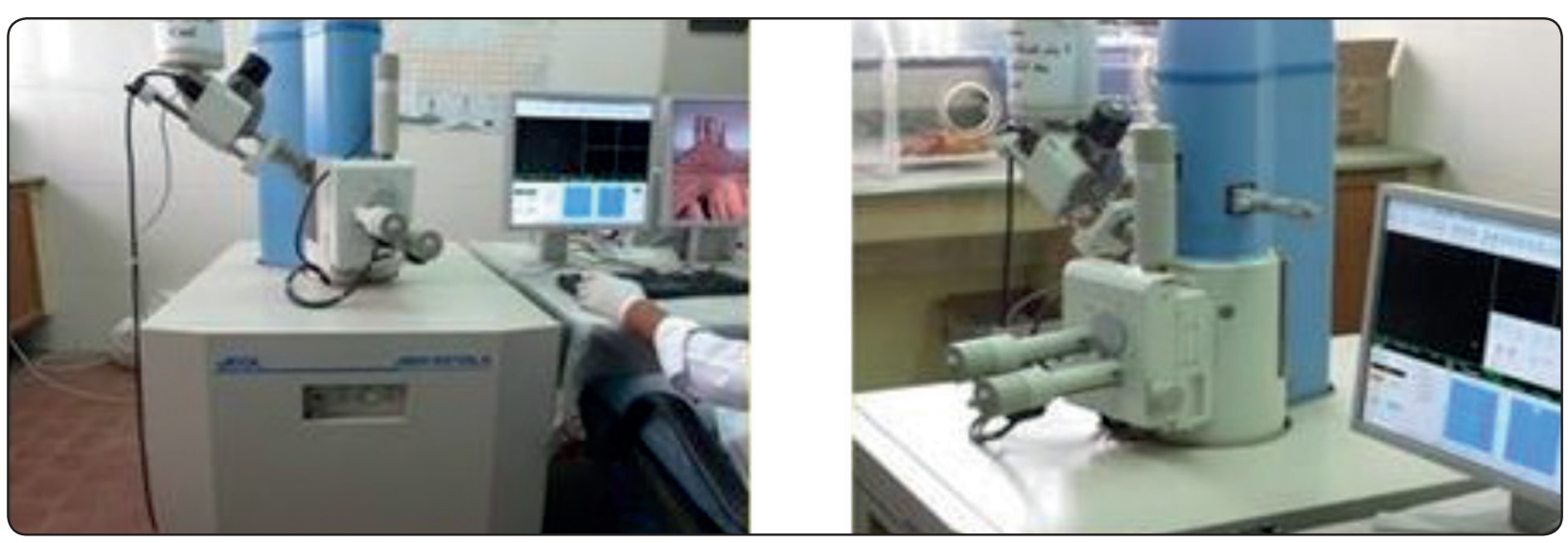

Fig. (2): Scanning electron microscopy -energy dispersive X ray analytical system (SEM-EDX). 


\section{RESULTS}

\section{SEM examination:}

- SEM examination of the enamel surface, of nonbonded enamel surface in Control group, occlusal to the orthodontic bonding area revealed almost normal topographic features of enamel (figure 3).

- SEM examination of the enamel surface of bonded enamel surface without primer (Group I : Orthomite LC) revealed initiation of enamel surface erosion at the region of adhesive resin layer and propagation along the bracket-resin interface. Also, enamel surface showing highly roughened enamel surface, deep areas of enamel erosions, erosions of enamel rod core, areas of destruction spread

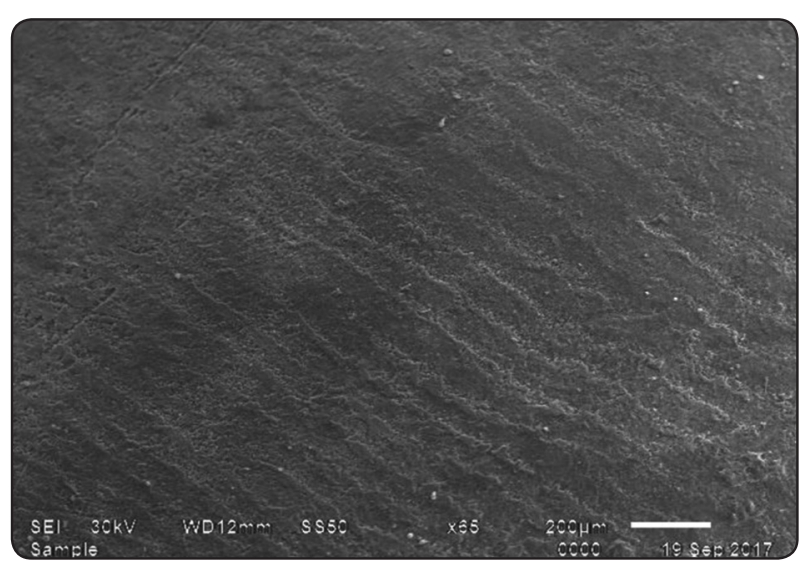

Fig. (3): SEM of enamel surface showing relatively smooth surface topographic features of enamel with an appearance similar to normal enamel.

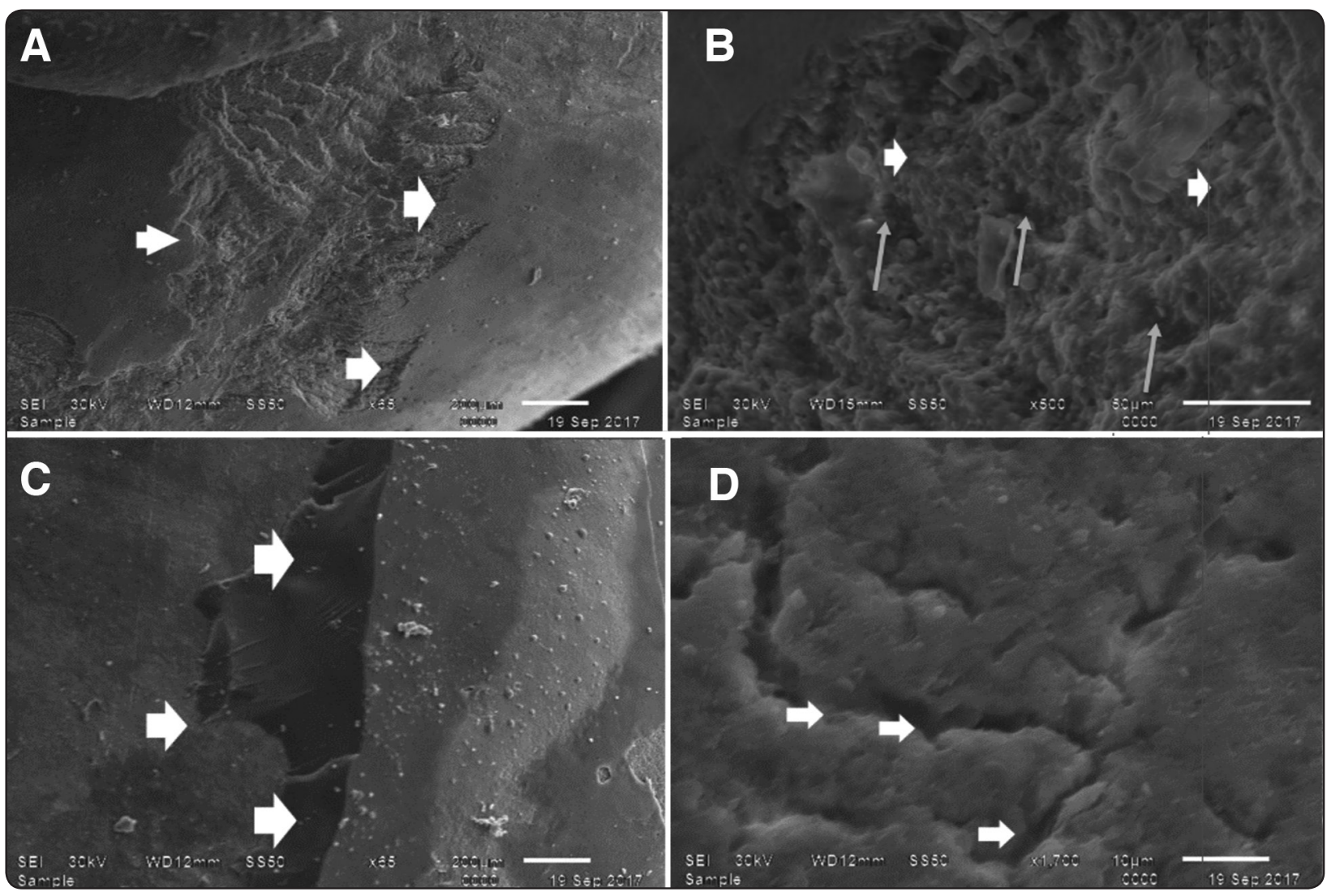

Fig. (4): A, SEM micrographs demonstrating the initiation of enamel surface erosion at the adhesive resin layer and propagation along the bracket-resin interface. B, SEM of enamel surface showing highly roughened enamel surface with deep areas of enamel erosions (arrows). There are erosions of enamel rod core (small arrows). C, SEM micrographs demonstrating the crack initiation at the adhesive resin layer and propagation along the bracket-resin interface. D, SEM of enamel surface showing enamel with surface erosions with areas of destruction spread throughout the enamel surface (small arrows). 

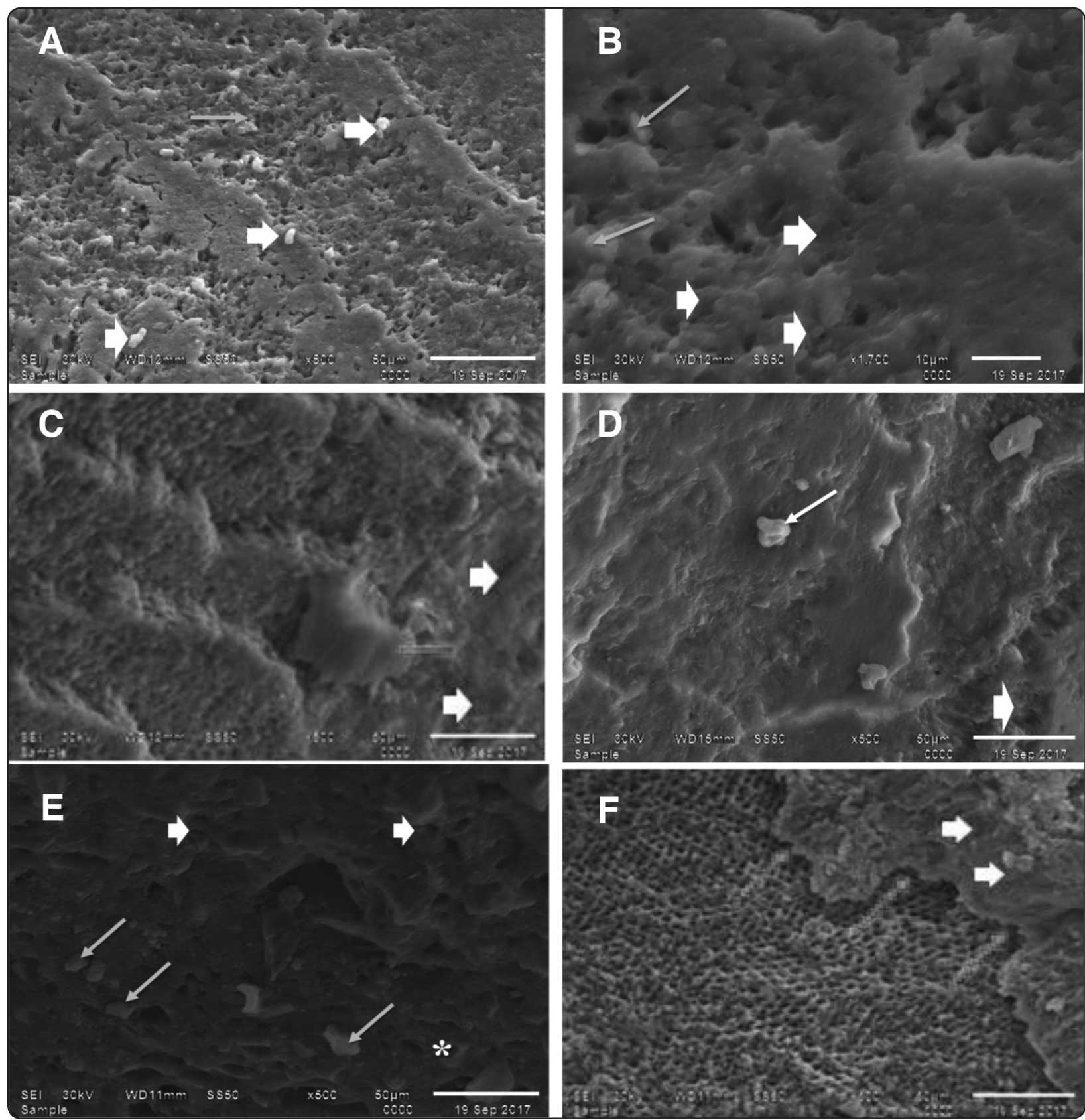

Fig. (5): A, SEM of enamel surface showing enamel rods appear with nearly regular orientation (arrows). Deposition of calcified globules all way of inter-rod region surrounding the enamel rods (red arrows). B, SEM of enamel surface showing globular calcification of enamel rod (arrows). Some enamel rods are occluded (red arrows). C, SEM of enamel surface showing enamel seemed to be re-mineralized with occluded enamel rods by globules (arrow). Enamel appeared to be repaired (red arrows). D, high power of $\mathrm{C}$ where enamel surface showing irregularly distributed globules over the enamel surface (arrow). Localized areas of enamel erosion in the form of accentuated focal holes (red arrow). E, SEM of enamel surface showing inter face of enamel surfaces erosions (arrows) and spread of calcified globules deposition (red arrows). F, SEM of enamel surface showing globular calcification of enamel rod peripheries (arrows). Some enamel rods are occluded (red arrows). Some enamel rods are completely obliterated $(*)$. 
throughout the enamel surface, crack initiate at the adhesive resin layer and propagate along the bracket- resin interface. Figure (4).

- In SEM examination of the enamel surface of bonded enamel surface with primer (Group II: Transbond $^{\mathrm{TM}} \mathrm{XT}$ ), enamel surface showing

Enamel rods appear with nearly regular orientation. Deposition of calcified globules of inter-rod region to gather with globular calcification of enamel rod and may be completely obliterated. Some enamel rods are nearly occluded with enamel surface seemed to be re-mineralized and repaired. In some sections the enamel surface showing revealed inter face of enamel surfaces erosions and spread of calcified globules deposition (Figure, 5).

The calcium and phosphorous mass percentages were measured and statically analyzed occlusal and gingival to the de-bonded brackets for both (group I and group II) and also for control group using scanning electron microscopy-energy dispersive $\mathrm{X}$ ray analytical system (SEM-EDX). The statistical analysis revealed that despite the lower calcium percentage in group (I) than group (II) or control group, there was non-significant difference in calcium mass percentage either orthodontic primer was used or not. (table1,2 and Figure 6,7)

TABLE (1) Comparative statistics of Calcium mass percentage between the studied groups

\begin{tabular}{|c|c|c|}
\hline Calcium mass $\%$ & Occlusal & Gingival \\
\hline Groups & Mean \pm SD & Mean \pm SD \\
\hline Group I & $69.53 \pm 3.65$ & $63.5 \pm 3.82$ \\
\hline Group II & $72.08 \pm 2.97$ & $66.64 \pm 2.87$ \\
\hline Control & $74.32 \pm 4.10$ & $69.25 \pm 4.21$ \\
\hline f-test & 2.524 & 2.851 \\
\hline P-value & 0.105 & 0.102 \\
\hline P1 & 0.135 & 0.174 \\
\hline P2 & 0.068 & 0.081 \\
\hline P3 & 0.169 & 0.123 \\
\hline
\end{tabular}

* Statistically significant at $P \leq 0.05 \quad P 1$ : group $1 \&$ control, P2: group II \& control, P3: group 1 \& group II

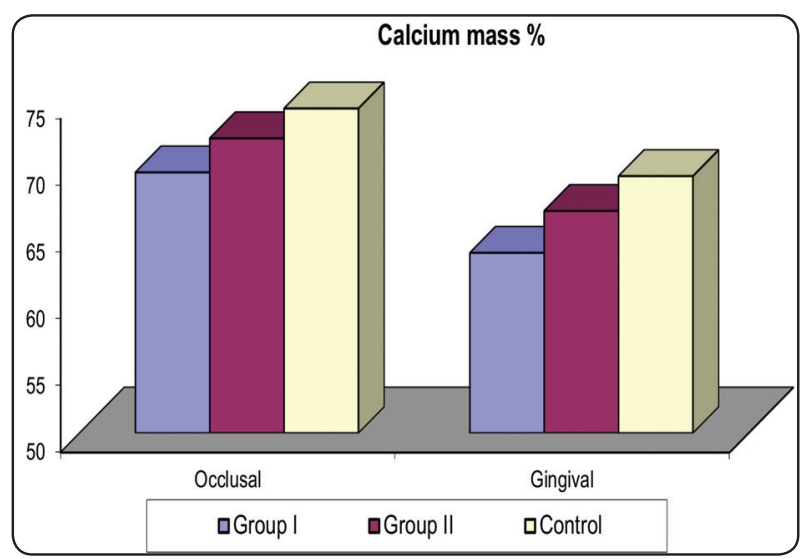

Fig. (6): EDX Descriptive statistics of calcium mass percentage occlusal and gingival in all groups

TABLE (3): Comparative statistics of phosphorous mass percentage between the studied groups

\begin{tabular}{|c|c|c|}
\hline Phosphorous mass $\%$ & Occlusal & Gingival \\
\hline Groups & Mean \pm SD & Mean \pm SD \\
\hline Group I & $27.75 \pm 2.97$ & $28.96 \pm 3.12$ \\
\hline Group II & $30.72 \pm 3.05$ & $32.11 \pm 3.31$ \\
\hline Control & $33.25 \pm 3.19$ & $35.45 \pm 3.59$ \\
\hline f-test & 2.364 & 2.541 \\
\hline P-value & 0.117 & 0.129 \\
\hline P1 & 0.157 & 0.160 \\
\hline P2 & 0.073 & 0.086 \\
\hline P3 & 0.235 & 0.165 \\
\hline
\end{tabular}

* Statistically significant at $P \leq 0.05$ P1: group $1 \&$ control, P2: group II \& control, P3: group 1 \& group II

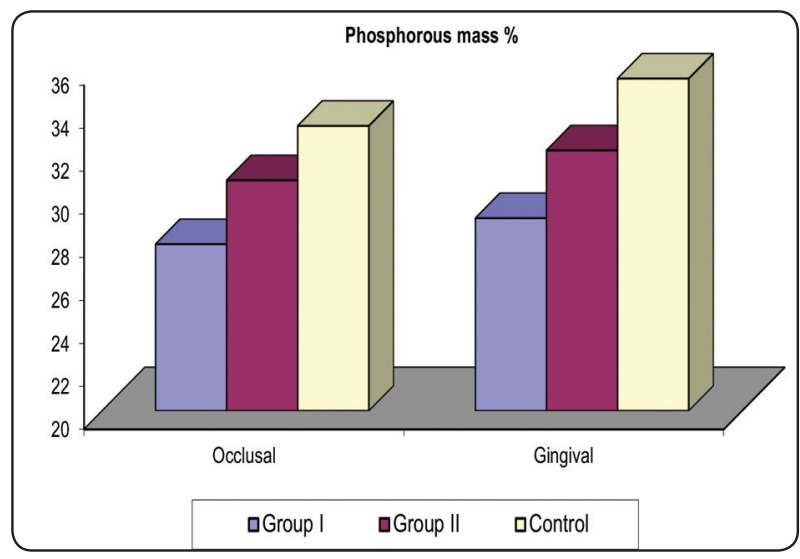

Fig. (7): EDX Descriptive statistics of phosphorous mass percentage occlusal and gingival in all groups 
TABLE (3): Comparative statistics of average calcium and phosphorous mass percentage between the studied groups

\begin{tabular}{|c|c|c|}
\hline & $\begin{array}{c}\text { Average Calcium } \\
\text { mass } \%\end{array}$ & $\begin{array}{c}\text { Average Phosphorous } \\
\text { mass } \%\end{array}$ \\
\hline Groups & Mean \pm SD & Mean \pm SD \\
\hline Group I & $67.52 \pm 3.28$ & $28.36 \pm 3.09$ \\
\hline Group II & $69.46 \pm 3.08$ & $31.42 \pm 3.27$ \\
\hline Control & $72.13 \pm 3.97$ & $34.35 \pm 4.14$ \\
\hline f-test & 2.112 & 2.281 \\
\hline P-value & 0.141 & 0.136 \\
\hline P1 & 0.179 & 0.167 \\
\hline P2 & 0.080 & 0.073 \\
\hline P3 & 0.107 & 0.123 \\
\hline
\end{tabular}

* Statistically significant at $P \leq 0.05$

P1: group 1 \& control, P2: group II \& control, P3: group 1 \& group II

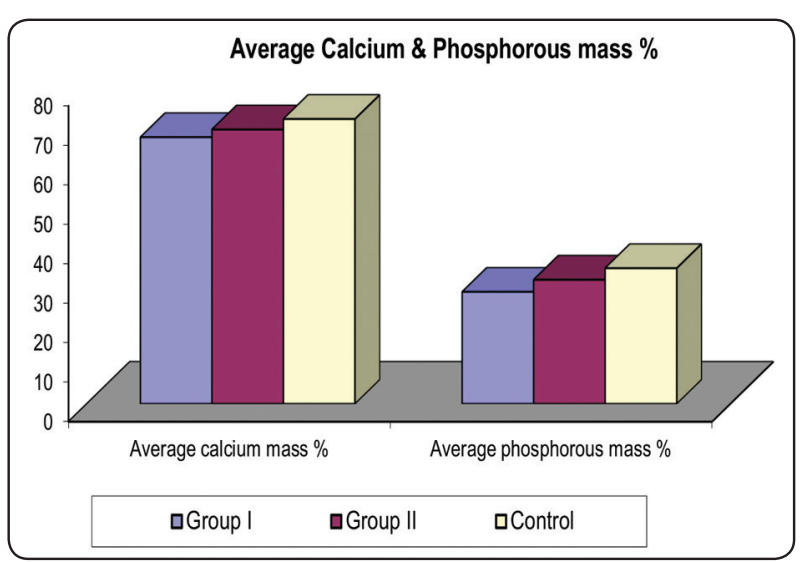

Fig. (8): EDX Descriptive statistics of average calcium and phosphorous mass percentage in all groups

\section{DISCUSSION}

Orthodontic practice have affected by advances in orthodontic materials, aimed to improve results and reduce treatment time by using efficient materials and convenient techniques. Thus, orthodontic brackets bonding without primer has appeared on the market, a previous report has shown that orthodontic primer have cytotoxicity for fibroblasts in gingival tissue ${ }^{(18)}$. Moreover, absence of prior adhesive resin may decrease wetness of the enamel, decreasing the amount of adhesive left on the tooth after bracket removal. ${ }^{(19)}$

The orthodontic adhesives should be studied in detail as micro gaps between the adhesive and the enamel surface, which might initiate unwanted effects on enamel surface ${ }^{(20)}$

Future researches on bonding brackets without primer are recommended in which multi-operator are participating with different levels of clinical experience.

The present in vivo clinical study was carried out over a period of six months despite the length of the study was determined three months to overcome the attrition bias till 10 patients per each group were finished. The three months period of this study was considered as adequate period as measurable demineralization can be observed around orthodontic appliance after one months of bonding the appliance as stated by numerous previous studies ${ }^{(21-23)}$ some of these focal holes are considered natural defects always present in sound enamel surface filled with organic matter and considered as initial sites for acid penetration.

The sample size (10 patients per each group) were determined statistically in order to obtain study power $80 \%$ so it is recommended in future studies to use a larger sample size to decreases the margin of error and increase the power of the study and decrease the risk of obtaining a false negative results. 
in order to obtain better patient compliance all patients included in the present study were adult females; as a clinical observation the adults are more careful than children and females are more careful than males.

Many previous studies emphasized on the effect of etching process, whereas the type of adhesive made no difference. ${ }^{(24,25)}$

As stated by Zachrisson and Büyükylimaz, 2005(26); The microspores of the etched enamel forms tags with the orthodontic resin to produce the bonding so the eaching process must be similar in both groups to eliminate the effect of different etching techniques. so the etch supplied with Orthomite LC (phosphoric acid 65\%) was replaced by phosphoric acid etch $37 \%$ The findings of this research show that the conventional multistep adhesive system with primer resulted in better but still non-significant difference in can affects the results enamel topographic structure with little areas of cracks and erosion than bonding without primer this came in accordance with Jendresen and Glantz $^{(27)}$ and others studies. ${ }^{(28-30)}$

The same conventional $37 \%$ ortho-phosphoric acid was used for a similar time (30 second) for acid etching step for both groups replacing the acid etch supplied with the Orthomite material to avoid confounding errors that can affects the results as etching step contribute with decalcification associated with orthodontic treatment as reported by numerous previous studies. ${ }^{(31,32)}$

Standardization of photo activation time in both study groups is very important factor which given a strong attention throughout the study to eliminate any variation due to curing time variation.

To avoid the bias resulted from investigator subconscious (as stated by Pandis N 2011) (33) believes of need of primer each patient enrolled in this study was coded by a code that did not reveal to both operator and statistical assessment operator to which group this patient belong till the outcome was obtained.

EDX is defined as qualitative, quantitative and semi quantitative technique for identification of a wide variety of chemical elements with a sensitivity depending on the atomic number of the element to be tested so calcium and phosphorus was tested, as their atomic number is 20,15 respectively and both elements are considered as caries preventing agents and if present during re-mineralization render enamel surface more resistant to future demineralization by enhancing crystal growth and encourages mineral precipitation. ${ }^{(34,35)}$

When compared group (I) and group (II) in the present study there was no statistically significant difference between the two groups. However, there were a greater enamel defects and lower calcium and phosphorus mass percentage in group (II); without the use of primer. Analysis of variance (ANOVA) has commonly been used to compare the results of three or more groups. The result of this study demonstrate no statistically significant difference when bonding with or without primer, these findings came in accordance with S.S. Nandhra et al.2015 and others numerous previous studies. ${ }^{(16,17,36)}$

\section{CONCLUSIONS}

Bonding of orthodontic braces without primer may produce greater enamel defects than bonding with primer in the form of enamel erosion, cracks and gaps between enamel rods and enamel surface.

-Both calcium and phosphorus mass percentage in the enamel decreased with larger but still nonsignificant values after three months of bonding without primer than bonding with primer.

\section{RECOMMENDATIONS}

Further studies are required on larger sample size and longer period of time to find out the effect of primer absence after the end of orthodontic treatment. 


\section{REFERENCES}

1. Zachrisson BU. Bonding in orthodontics. In: Graber TM, editor. Orthodontics: current principles and techniques. St Louis, MO: Elsevier Mosby; 2005. p. 579-659.

2. Pasquale A, Weinstein M, Borislow AJ, Braitman LE. Invivo prospective comparison of bond failure rates of 2 selfetching primer/adhesive systems. Am J Orthod Dentofacial Orthop 2007;132:671-4.

3. Arhun N, Arman A, Cehreli SB, Arikan S, Karabulut E, Gülsahi K. Microleakage beneath ceramic and metal brackets bonded with a conventional and an antibacterial adhesive system. Angle Orthod 2006;76:1028-34.

4. Attar N, Taner TU, Tülümen E, Korkmaz Y. Shear bond strength of orthodontic brackets bonded using conventional vs one and two step self-etching/adhesive systems. Angle Orthod 2007;77:518-23.

5. Scribante A, Sfondrini MF, Fraticelli D, Daina P, Tamagnone A, Gandini P. The influence of no-primer adhesives and anchor pylons bracket bases on shear bond strength of orthodontic brackets. BioMed Res Int. 2013;2013:1-6.

6. Tecco S, Traini T, Caputi S, Festa F, de Luca V, D'Attilio M. A new one-step dental flowable composite for orthodontic use: an in vitro bond strength study. Angle Orthod. 2005;75: 672-677.

7. Scribante A, Sfondrini MF, Fraticelli D, Daina P, Tamagnone A, Gandini P. The influence of no-primer adhesives and anchor pylons bracket bases on shear bond strength of orthodontic brackets. BioMed Res Int. 2013;2013:1-6.

8. Naidu E, Stawarczyk B, Tawakoli PN, Attin R, Attin T, Wiegand A. Shear bond strength of orthodontic resins after caries infiltrant preconditioning. Angle Orthod. 2013;83: 306-312.

9. O'Brien KD, Watts DC, Read MJ. Light cured direct bonding - is it necessary to use primer? Eur J Orthod 1991;13(1):22-6.

10. Wang WN, Tarng TH. Evaluation of the sealant in orthodontic bonding. Am J Orthod Dentofacial Orthop 1991;100:209-11.

11. Tang AT, Bjorkman L, Adamczak E, Andlin-Sobocki A, Ekstrand J. In vitro shear bond strength of orthodontic bondings without liquid resin. Acta Odontol Scand 2000;58:44-8.
12. Uysalt, Sari Z, Demira. Are the flowable composites suitable for orthodontic bracket bonding? Angle Orthod 2004;74:697-702.

13. Tecco S, Traini T, Caputi S, Festa F, De Luca V, D'attilio M. A new one-step dental flowable composite for orthodontic use: an in vitro bond strength study. Angle Orthod 2005;75:672-7.

14. Ryou DB, Park HS, Kim KH, Kwon TY. Use of flowable composites for orthodontic bracket bonding. Angle Orthod 2008;78:1105-9.

15. Bazargani F, Jacobson S, Lennartsson B. A comparative evaluation of lingual retainer failure bonded with or without liquid resin. Angle Orthod 2012;82:84-7.

16. Tang AT, Bjorkman L, Lindback KF, Andlin-Sobocki A, Ekstrand J. Retrospective study of orthodontic bonding without liquid resin. Am J Orthod Dentofacial Orthop 2000;118:300-6.

17. Banks PA, Richmond S. Enamel sealants: a clinical evaluation of their value during fixed appliance therapy. Eur J Orthod 1994;16:19-25.

18. Tang AT,Liu Y,Bjorkman L,Ekstrand J. In vitro cytotoxicity of orthodontic bonding resins on human oral fibroblasts. Am J Orthod Dentofacial Orthop. 1999;116:132-138.

19. Tecco S, Traini T, Caputi S, Festa F, de Luca V, D'Attilio M. A new one-step dental flowable composite for orthodontic use: an in vitro bond strength study. Angle Orthod. 2005;75: 672-677.

20.Arhun N, Arman A, Cehreli SB, Arikan S, Karabulut E, Gulsahi K. Microleakage beneath ceramic and metal brackets bonded with a conventional and an antibacterial adhesive system. Angle Orthod. 2006;76:1028-1034.

21. Ogaard B, Rolla G, Arends J and Ten Cate JM.Orthodontic appliances and enamel demineralization part2, prevension and treatment of lesions.Am J Orthod Dentofac Orthop.1988;94:123-28.

22. Christoffersen J, Arends J.Progress of artificial carious lesions in enamel.Caries Res.1982;16:433-9.

23. Haikel Y, Frank RM and Voegel JC.Scanning Electron Microscopy of the human enamel surface layer of incipient carious lesions. Canes Res.1983;17:1-13.

24. Li ZM, Chen SH, Liu XQ, Chen J, Li NY. Effect of bonding materials and methods on microleakage around the edge of stainless-steel brackets: an in vitro study. Shangai Kou Qiang Yi Xue. 2005;14:645-647. 
25. Yagci A, Uysal T, Ulker M, Ramoglu SI. Microleakage under orthodontic brackets bonded with the custom base indirect bonding technique. Eur J Orthod. 2010;32:259263.

26. Zachrisson B Ü, Büyükylimaz $\mathrm{T} 2005$ Bonding in orthodontics. In: Graber T M, Vanarsdall R L Jr, Vig K W L (eds). Orthodontics current principles and techniques, 4th edn. Elsevier Mosby Co., St Louis, p. 582

27. Jendresen MD, Glantz PO. Clinical adhesiveness of selected dental materials. An in-vivo study. Acta Odontol Scand. 1981;39:39-45.

28. Naidu E, Stawarczyk B, Tawakoli PN, Attin R, Attin T, Wiegand A. Shear bond strength of orthodontic resins after caries infiltrant preconditioning. Angle Orthod. 2013;83: 306-312.

29. Shahabi M, Heravi F, Mokhber N, Karamad R, Bishara SE. Effects on shear bond strength and the enamel surface with an enamel bonding agent. Am J Orthod Dentofacial Orthop. 2010;137:375-378.

30. Vicente A, Bravo LA, Romero M, Ortiz AJ, Canteras M. Effects of 3 adhesion promoters on the shear bond strength of orthodontic brackets: an in-vitro study. Am J Orthod Dentofacial Orthop. 2006;129:390-395
31. O'Reilly MM, Featherstone JD.Demineralization and remineralization around orthodontic appliances: an in vivo study.Am J Orthod Dentofac Orthop.1987;92:33-40.

32. Legler LR, Retief DH, Bradley E.effects of phosphoric acid concentration and etch duration on enamel depth of etch:an in vitro study.Am J Orthod Dentofac Orthop.1990;98:154-160.

33. Pandis N. Sources of bias in clinical trials. Am J Orthod Dentofacial Orthop 2011;140:2.

34. Gontijo L, Cruz Rde A and Brandaoa' PR. Dental enamel around orthodontic appliances after fluoride varnish application. Braz Dent J.2007;18:49-53.

35. koulourides T, Keller SE, Manson-Hing L and Lilley V.Enhancement of fluoride effectiveness by experimental cariogenic priming of human enamel.Caries Res. 1980; 14:32-9.

36. Nandhra S.S., Simon J. Littlewood S. J., Houghton N, Luther F, Prabhu J, Munyombwe T and Wood S. R. Do we need primer for orthodontic bonding? A randomized controlled trial. European Journal of Orthodontics, 2015; $147-155$. 